\title{
Acute scrotum in a 8-year-old italian child caused by extraintestinal anisakiasis in a seaside area.
}

\author{
ANTONELla CENTONZE ${ }^{1}$, Stellario Capillo ${ }^{1}$, Aurelio Mazzei ${ }^{1}$, Domenico Salerno ${ }^{1}$, \\ Domenico Sinopoli ${ }^{1}$, ILARIA PROSPERI PORTA ${ }^{2}$, and EMANUELE BALDASSARRE ${ }^{2}$ \\ ${ }^{1}$ Pugliese Ciaccio Hospital \\ ${ }^{2}$ AUSL Aosta
}

June 18, 2020

Dear Editor,

we read with great interest the article recently published by Morishima L et al. (1 ). The Authors report an high incidence of Anisakis-specific IgE antiboides in patients with anaphylaxis in two towns in Japan.Worlwide the incidence of Anisakis patients is related to the ingestion of raw fish in seaside places. Herein we present the case of a child who has experienced an anaphylaxis with acute respiratory symptoms and a strange scrotal mass, in Calabria, a region completely surrounded by the sea in Southern Italy.

An 8-year-old child italian child referred to our Emergency Department with a clinical complaint characterized by acute respiratory distress and right testicular pain since almost 24 hours, that worsened during the day. The respiratory picture resolved almost immediately with the use of corticosteroids via i.v. The clinical examination showed the presence of a painful testicle-independent swelling of about $1 \mathrm{~cm}$ in diameter, between the perineal plane and the scrotum, in the absence of signs of inflammation.

The doppler ultrasonography demonstrated the presence of phlogistic area at the level of the right epididymis. We decide for home observation and medical therapy (betamethasone and amoxy-clavulanic acid) with mild improvement in symptoms in the following 3 days.

After 4 days the child came back to our attention with an important scrotal lymphadenitis consensual to the previous epididymitis, with erythematous and warm scrotal skin. The intense scrotal pain, as in a clinical picture of acute scrotum, did not allow to visit the boy correctly.

A second US showed an independent mass from the testicle of about $1 \mathrm{~cm}$.

The laboratory findings were completely negative, including testicular markers for tumour.

The formula was; white blood cells 5.800, Neutrophiles 48.9\%, Lymphocytes 41.8\%, Eosinophils 0.8\%. At surgical exploration the testicle was normal and a paratesticular granulomatous mass of about $2 \mathrm{~cm}$ in diameter was removed.

The section of the anatomical specimen in the operatory room left us speechless.

Inside the operating specimen we found ... Worms! The histological examination confirmed a case of extra-gastrointestinal anisakiasis.

(FIG.1)

The child was treated with Albendazole $400 \mathrm{mg}$ per day for 10 days. After 15 days the pancolonoscopy was negative for intestinal parasitic lesions. 
This case demonstrates that anisakiasis could present with undefined symptoms, as expression of its extraintestinal location. Generally the suspicion is raised with a recent ingestion of raw or undercooked meats, like sushi. (2) In Anisakis infection, the human is an "accidental host" after ingestion of the third-stage encysted larvae in infected fish. The worms progress through the tissues invading the bowel wall, contributing to the formation of intramural or extraintestinal eosinophilic granulomas, when they cross the wall. (3)

An extraintestinal anisakiasis is anecdotal and to our knowledges only two cases have been reported in the literature (2-4) . Herein we present the first case of anaphilaxis and scrotal localization in paediatric age. In literature we found only few cases of scrotal infestation by filariae, mimicking a testicular tumor. (5)

This child lives in Calabria, a Region in the South of Italy, in a normal italian socio-economic and hygienic conditions context. He hasn't traveled in the past two years and he never has intaken raw fish or he has gone to a sushi restaurant. There were no similar cases in school.

Whether the entrance door of the anisakis remains a mystery, a possible theory on the etiopathogenesis of this case could be related to the persistence of a patent vaginal peritoneum duct, with the migration of worms from the intestinal wall to the scrotum. However, the child had no signs of hydrocele or inguinal swelling.

\section{REFERENCES}

1. Morishima, R., Motojima, S., Tsuneishi, D., Kimura, T., Nakashita, T., Fudouji, J., Ichikawa, S., Ito, H., \& Nishino, H. (2020). Anisakis is a major cause of anaphylaxis in seaside areas: An epidemiological study in Japan. Allergy, 75 (2), 441-444.

2. Allison C, Baumann M. A Case Report of Adhesional Small Bowel Obstruction Caused by Extraintestinal Anisakiasis. J Emerg Med. 2019;57(6):e175-e179.

3. Takabayashi T, Mochizuki T, Otani N, Nishiyama K, Ishimatsu S. Anisakiasis presenting to the ED: clinical manifestations, time course, hematologic tests, computed tomographic findings, and treatment. Am J Emerg Med. 2014;32(12):1485-1489.

4. Takamizawa Y, Kobayashi Y. Adhesive intestinal obstruction caused by extragastrointestinal anisakiasis. Am J Trop Med Hyg. 2015;92(4):675-676.

5. Ho CC, Ideris N. Testicular mass: do not forget filariasis. Infection. 2013;41(4):893-896.

\section{FIGURES}

FIGURE 1

The specimen

WE STATE THE WE HAVE NOT RECEIVED FUNDING SOURCES AND THAT NO CONFLICTS OF INTEREST ARE PRESENT. 


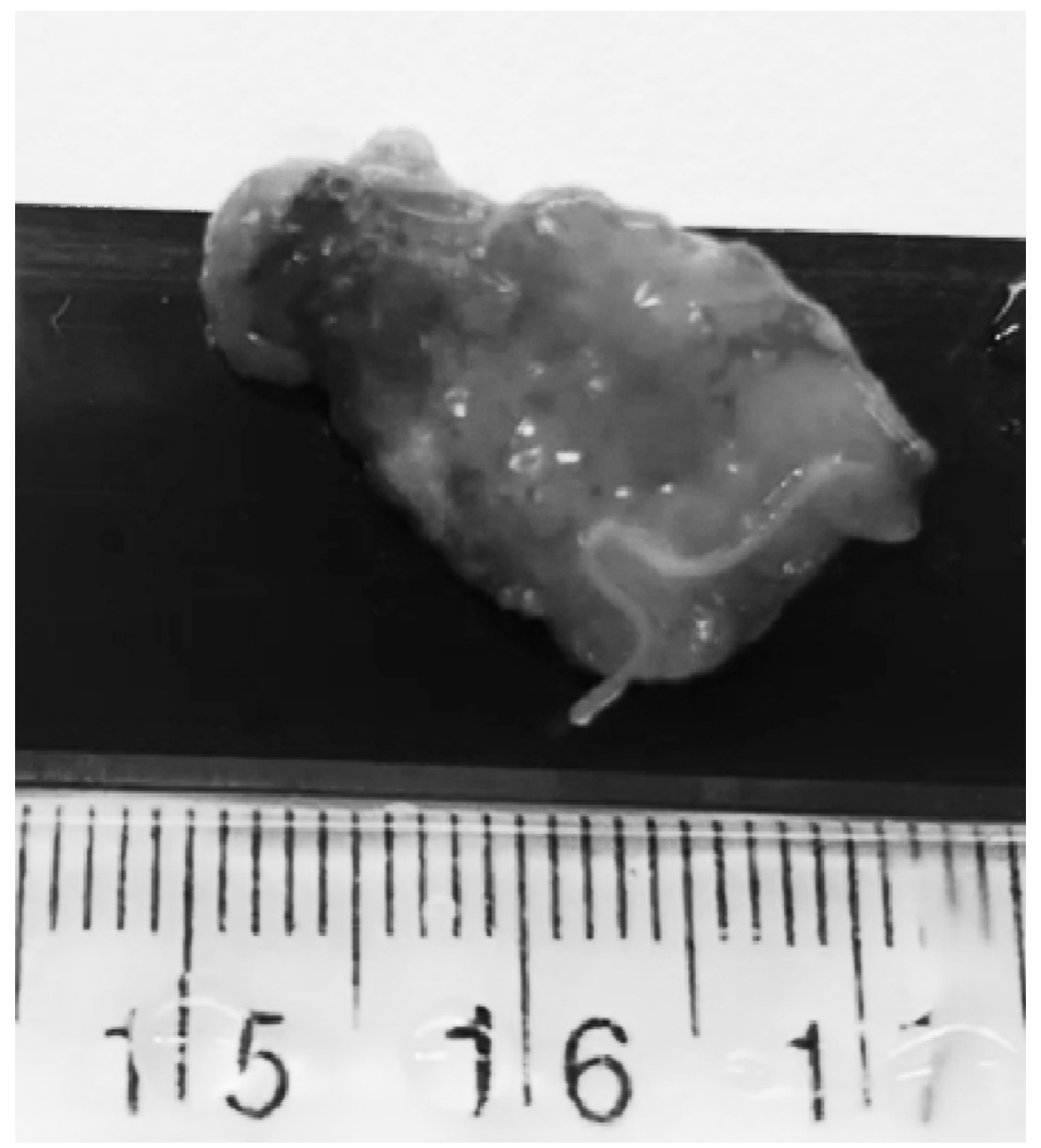

